East African Medical Journal Vol. 80. No. 7 July 2003

MIDLINE LETHAL GRANULOMA COMPLICATING PREGNANCY: CASE REPORT

B.D.O. Saheeb, BDS, FWACS, FICS, FDS, RCS (Edin) Senior Lecturer/Consultant, and M.A. Ojo, BDS, MMed Sc, Dip Maxfac Rad, Associate Professor/Consultant Department of oral and Maxillofacial Surgery and Pathology, University of Benin Teaching Hospltal, Benin City, Nigeria.

Request for reprints to: Dr. B.D.O. Saheeb, P.O Box 2799, Benin City, Edo State, 300-001, Nigeria

\title{
MIDLINE LETHAL GRANULOMA COMPLICATING PREGNANCY: CASE REPORT
}

\author{
B.D.O. SAHEEB and M.A. OJO
}

\begin{abstract}
A case of midline lethal granuloma in a 28-year- old female Nigerian patient is reported. Oral, ocular and nasal lesions were present and these preceded a spontaneous abortion of a three month old pregnancy. The clinical course of the disease and its similarity to other granulomatous diseases, which are generally classified as midline granuloma syndrome, are highlighted. The prognosis is poor but early diagnosis and treatment appears to improve a patient's condition
\end{abstract}

\section{INTRODUCTION}

The term "midline granuloma syndrome" (MGS) is clinically used to describe a abroad spectrum of diseases characterised by aggressive and progressive destruction of the mucosa and adjacent structures of the midline and upper respiratory tract (1). Since Wegener (2), first described three patients with a condition starting as rhinitis with disseminated disease and ending in renal failure, a number of cases have been reported in the American and European literature.

The term "Wegener granulomatosis" (WG) has been adopted when the systemic aspect of the disease are recognised (3). Although it was the first recognised cause of these syndromes, its clinical relationship to nasopharyngeal T-cell lymphoma in its early states has been emphasised (2). Some authorities $(3,4)$, recognise that midline lethal granuloma (MLG) and WG are one and the same disease but differentiated by systemic involvement of the latter. The uncertainties surrounding the clinical and pathological presentation of these diseases, which are similar, are demonstrated by these confusing suggestions. These are further compounded by the view of some authorities that frown at the blanket use of the term "midline lethal granuloma" - arguing that not all are lethal and clearly not all are granulomatous (5), nor do they all begin in the midline (6).

The MLG and WG may be rare in Africa. Adekeye (7), in 1977 was only able to find three references to the diseases in Africa. Furthermore, he reported three cases of the MLG and WG in Nigerians. The purpose of this paper was to report a case of midline lethal granuloma complicating pregnancy in the hope that it will also add to the literature of the few cases reported from Africa.

\section{CASE REPORT}

A 28-year-old Nigerian woman presented in our Oral and Maxillofacial Surgery clinic with a history of oro-nasal fenestration and swelling of the left eye of a 4-month duration. She had complained of a gradual deterioration of vision in the left eye and a purulent discharge from the nose. There was no previous extraction of her teeth or trauma. She had observed that three days before the oral and ocular symptoms, she had a spontaneous abortion of a 3-month-old pregnancy.

On clinical examination, she was a fit and apparently healthy looking female with swelling of the left eye. She was neither clinically pale nor jaundiced. There was no obvious discharge from the nose. A palatal opening measuring about 2.5 $\mathrm{cm} \times 2.2 \mathrm{~cm}$ was obvious on the hard palate. The margins of the opening were ragged exposing necrotic bone on the right border. There was a gradual infiltration into the nose exposing the septum, which was visible from the palate.

She was referred to the ophthalmology clinic for evaluation of the left eye. She had an ultrasound done and the report showed eyeball which were normal in outline, size and chamber differentiation. The lenses were reported to have been an intact in position and normal. There was no evidence of retinal detachment, vitreous haemorrhage, retrobulbar lesion or mass. Laboratory examination of the patient's blood showed a haemoglobin of $11 \mathrm{~g} / 100 \mathrm{ml}, \mathrm{PCV}$ of $33 \%$, WBC of 4,400ul, ESR of $36 \mathrm{mmol}^{-1}$ Westerngreen. There were negative VDRL, Mantoux and HIV tests. Bacteriological cultures of swabs taken from the lesion produced normal commensals. A tentative diagnosis of Wegener's granulomatosis was made with, syphilitic gumma, midline non-healing granuloma, peripheral T-cell lymphoma, idiopathic midline destructive disease and polyarteritis nodosa as differentials.

A biopsy of the lesion was taken from the non-necrotic part. The histology report showed vasculitis, inflammatory cell infiltrate of the arterial walls with destruction of the normal architecture and fibrinoid deposits in many vessels. Some arterial vessels showed persistent lumina with chronic inflammatory cells infiltrating the walls (Figure 1). The covering mucosa and submucosa were also infiltrated by chronic inflammatory cells, which were predominantly lymphocytes. 
Figure 1

Vasculitis of small arterioles with a chronic inflammatory cell infliltrate of the walls/stroma deep to the edge of the palatal ulcer. $H \& E X 128$

No giant cells were seen. These features are consistent with midline lethal granuloma. The patient was immediately commenced on azathioprine $150 \mathrm{mg}$ and $10 \mathrm{mg}$ of prednisolone daily for one week, which was to be reviewed with or without improvement of the patient. There was slight improvement in the patient's condition as the disease did not progress further after one week of treatment. However, the patient voluntarily discharged herself to seek alternative treatment.

\section{DISCUSSION}

The existence of a destructive granuloma of the face whose natural history is different from that seen in the nasal lesion of WG has long been recognised (8). It is a rare disease which was originally thought to be due to an excessive inflammatory reaction but which many now believe to be an atypical form of lymphoma (9). These lesions belong to a group of disorders whose clinicopathological course is similar. They are generally classified as midline granuloma syndrome. Two distinct types are recognised, as WG and the Stewart type (3). The latter lesions have been known by various clinical descriptive terms such as non-healing midline granuloma (NHMG) (9), MLG (7), and malignant granuloma (MG) (4). A third clinicopathologic sub-classification termed idiopathic midline destructive disease (IMDD) has also been described but there are doubts now whether this form exists (1). It has been emphasised that after the exclusion of WG, nearly all the remaining cases presenting as MGS are peripheral sinonasal angiocentric T- and/ or NK-cell lymphomas (1). The controversy that arose about these diseases was due to their close resemblance and their noncomprehensive study.

The clinical course of MLG is aggressive and destructive. The lesions appear clinically as aggressive progressive necrotic ulcers, which are non-healing, and this was the clinical course of the disease in our patient, which aided our diagnosis. The patient had a spontaneous abortion three days before oral and ocular symptoms and whether this scenario could be linked to hyperimmune response remains speculative. We could only find one case of WG complicating pregnancy in the literature (10), but no similar case report of the MLG could be found. The patient was reported to have had a normal full term delivery after receiving treatment with azathioprine.

The treatment of this disease has varied from the use of radiation therapy to corticosteroid and chemotherapy. Some cases have responded to a low dose of radiotherapy but relapses were common. High doses produced a much higher cure rate but were also associated with extensive tissue loss (10). Although steroids are considered by most to be contraindicated and potentially harmful some clinicians have used them in combination with cyclophosphamide and achieved poor results (7). Others have achieved success with a combination of azathioprine and prednisolone (10). We used this combination in our patient and achieved minimal improvement as there was no deterioration in the patient's condition. However, selfdischarge of the patient prevented long-term evaluation of treatment. The poor prognosis of MLG is well known. The need to diagnose the disease early, correct biopsy technique, the use of T-cell markers where available to eliminate lymphomas, aggressive and appropriate use of steroids and cytotoxic chemotherapy treatments are recommended.

\section{ACKNOWLEDGEMENT}

We wish to express our deep appreciation and gratitude to the Chief Medical Director of the University of Benin Teaching hospital Benin City, Nigeria for giving us the permission to publish the information on this patient who was managed in his hospital.

\section{REFERENCES}

1. Koch, M., Blatterspiel, G.J., Niedobiteck, G. and Constatinidis, J. Angiocentric T/NK cell lymphoma: a special clinicalpathological entity of lethal midline granuloma: a case report. Laryngorhinootologic. 2001; 80:410-415.

2. Wegener, F. Ueber generalisierte, septisuche Gefaesserkrankungen. Verh Dtsch Ges Pathol. 1937; 29: 202-210.

3. Friedmann, I. Midline granuloma. Proceedings of the Royal Society of Medicine. 1964; 57:289-297.

4. Mills, C.P. Malignant granulomas and Wegener's granulomatosis. Hosp. Med. 1967; 2:183-188.

5. Batsakis, J. Wegener's granulomatosis and midline (nonhealing) granuloma. Head and Neck Surg. 1979; 1:213-222.

6. Mills, C.P. The clinical diagnosis of malignant granulomata and Wegener's granulomatosis. Proceedings of the Royal society of Medicine. 1964; 57:297-299.

7. Adekeye, E.O., and Abengowe, C.V. Midline lethal granuloma and Wegener's granulomatosis in Nigerians: a report of three cases. Trop. Doctor. 1977; 7:169-174.

8. Suen, J.Y., Myers, E.N (eds). Unusual tumours In: Cancer of

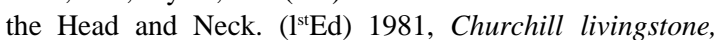
Edinburgh. 650-698.

9. Leading article. Non- healing midline granuloma. Lancet. 1977; 1296.

10. Cooper, K, Stafford, J. and Warwick, M.T. Wegener's granulomatosis complicating pregnancy. J. Obst. Gynaec. Brit. Cmwlth. 1970; 77:1028-1030. 